\title{
Zinc level in children with short stature
}

\author{
Tamila Sorokman', Snizhana Sokolnyk', Alexandra-Maria Popelyuk², \\ Olena Makarova ${ }^{3}$, Tatiana Bezruk ${ }^{4}$, Pavlo Moldovan ${ }^{5}$ \\ ${ }^{1}$ Department of Pediatrics and Medical Genetics Bukovinian State Medical University, Chernivtsi, Ukraine \\ ${ }^{2}$ Department of human anatomy Mykola Turkevich Bukovinian State Medical University, \\ Chernivtsi, Ukraine \\ ${ }^{3}$ Departmentnursing of higher nursing education Bukovinian State Medical University, Chernivtsi, Ukraine \\ ${ }^{4}$ Department of Internal Medicine Bukovinian State Medical University, Chernivtsi, Ukraine \\ 5"Bukintermed" laboratory, Chernivtsi, Ukraine
}

\begin{abstract}
Introduction. The research carried out confirms the great importance of zinc in the processes of children'sgrowth and development.

Aim. To investigate the zinc content in blood serum of children with short stature.

Methods. We examined 42 children under supervision in the children's endocrinology department of the Chernivtsi Oblast Children's Hospital during 2011-2018, aged 3 to 15 years. The control group consisted of 44 children aged 3-15 years. Determined the level of growth hormone (GR), IGF-1 and zinc in the blood plasma.

Results. It has been detected that the level of zinc in blood plasma is reducedin $90,4 \%$ of children with short stature. On average, zinc level in the blood plasma of children with short stature was $0.71 \pm 0.03 \mu \mathrm{g} / \mathrm{ml}$, which is significantly lower $(p<0.001)$ than the mean zinc level in children in the control group $-1.11 \pm 0.02 \mu \mathrm{g} / \mathrm{ml}$. In all age groups, there was a significant decrease in zinc values in plasma compared to those in the corresponding age group of the control group. In 28 (cases the level of zinc was quite low, in 10 cases it was very low and in the rest of the cases it had boundary indices. Indices of zinc in blood plasma in children with somatotropic insufficiency were the lowest and averaged $0.66 \pm 0.03 \mu \mathrm{g} / \mathrm{l}, \mathrm{p}<0.05$. Age and gender dependency of zinc level in blood plasma was not found.

Conclusions. Zinc deficiency in plasma is observed in most children with short stature. Necessary for zinc deficiency correction in patients with short stature by diet expansion incorporating food enriched with the microelement or the designation of appropriate zinc preparations. Diet expansion may be the subject of further research.
\end{abstract}

Keywords: children, short stature, zinc deficiency

\begin{abstract}
Abbreviations
EM - essential micronutrients, GH - growth hormone, SDS - standard deviation, GR - growth rate, BA - bone age, OC - ossification coefficient, BMI - body mass index, GH-IGF - growth hormone-insulin growth factor, IGFBP-3 - insulin growth factor binding protein-3, GHD - growth hormone deficiency, IFG-1 - insulin growth factor 1
\end{abstract}

\section{INTRODUCTION}

The problem of growth retardation in children is one of the most timely in pediatrics due to the high medical and social significance, the disabling nature of the pathology as well as the poor response to therapy. The key role of the microelements in the function- ing of all human organs and systems is pointed out in scientific studies [1-4]. A special emphasis is paid to the study of essential micronutrients (EM) impacton human health, and children with growth retardation in particular [5-7]. Zinc is one of these EM [8], being a part of more than 300 metal enzymes, it is involved in cellular metabolism, immune system functioning [9], 
growth and reproduction processes as well as having a membrane-stabilizing activity and has low accumulation ability [10-12]. The population frequency of zinc deficiency in Ukraine is unknown, because such studies were not conducted. Human growth is an integral health index as well as harmonious systems'interaction indicator. However, there are many reasons that can cause a deviation in the growth of the childby violating this natural harmony [13]. A key feature of the mineral metabolism in children is that the entering and the elimination of mineral substances in the body processes are unbalanced [14]. It was detected that the lack of zinc inhibits the growth of long bones in the embryos of mice. A shortening of diaphyses, narrowing of the chondrocyte zone, increasing the number of osteoblasts, ripening of chondrocytes with an increase in osteoclastic activity were detected $[15,16]$. The scientists proved that zinc content is even more important for the bone matrix formation during fetal development, than mineralization of bone matrix. Zinc deficiency is embryoptic in vivo, embryos have a small length and significant delay in the development of organs; adding zinc to the diet of rats significantly reduces this negative effect [17-18].

The conducted scientific researches confirm the great importance of zinc in the processes of growth and development of children [19-24].

Zinc deficiency could be related to overactivity of the enzyme $\mathrm{Cu} / \mathrm{Zn}$ Superoxide Dismutase in these individuals. As a result of this overactivity, individuals with growth deficit are in a state of continuous Oxidative Stress [25,26]. Energy and micronutrient deficiency remain prevalent among children. The fortified juice drink was effective in reducing the prevalence of growth deficit and improved the zinc status of children [27,28]. Zinc is an important nutrient which is critical for normal immune function and physical growth. Zinc deficiency seems to be common in developing countries and that makes children in those countries prone to infectious diseases. In countries where zinc deficiency is common; zinc supplementation has been shown to reduce the rates of diarrhea and to enhance the physical growth of children at risk of stunting [29-30].

According to the "Consensus Guidelines for Diagnosis and Treatment of Growth Hormone (GH) Deficiency in Childhood and Adolescents: Summary Statement of the GH Research Society" (1999), the short stature is classified as follows:

- primary growth disorders caused by internal defects of the bones and connective tissue as a result of a genetic defect or prenatal damage are often accompanied by dysmorphic features and disproportionate body structure;
- secondary growth disorderscaused by factors that are manifested outside the bone and connective tissue - systemic, endocrine, metabolic, iatrogenic and psychogenic disorders;

- idiopathic low-growth diagnosed in cases where the child has a normal body weight and height at birth, proportional body structure, has no endocrine or organic disorders, psychosocial problems and eats properly. Familial and non-familialshort stature are also detected in the case. Non-familial short staturecombined with latent puberty are defined as constitutional growth and maturationretardation.

\section{AIM}

To investigate the zinc content in blood serum of children with short stature.

\section{METHODS}

42 children under supervision in the children's endocrinology department Chernivtsi Oblast Children's Hospital during 2011-2018 aged 3 to 15 years old (average age of $8.96 \pm 0.19)$ were screened. Among them 28 boys (66.7\%) and 14 girls (33.3\%) with different forms ofshort stature. Criteria for inclusion in the research wereshort stature, age from 3 to 15 years, residence on the territory of Chernivtsi region. Exclusion criteria were acute infectious disease, chronic somatic pathology, malabsorption syndrome, metabolic diseases, genetic and mental illnesses, residence outside the Chernivtsi region, parental refusal for examination. The control group consisted of 44 children aged $3-15$ years, whose average age was $9.16 \pm 0.45$ years, 24 (54.5\%)boys, 20 (45.4\%)girls. These patients did not have any growth and sexual development retardation, somatic, genetic and endocrine pathology. Before the start of the survey, patients' and their parental consent were obtained to participate in the study and use the data. Ageneral clinical study, anthropometry (measurements of height with the help of the "System Dr. KellerJ." Stadiometer, body mass measurements using SECA electronic weights, standard deviation score (SDS) for growth and body weight for the use of percentile curves, growth rate (GR), SDS of growth rate, bone age (BA), bone marrow retardation, ossification coefficient (OC), body mass index (BMI))were conducted for all children. Normally, the gap was between minus 1 SDS and plus $1 \mathrm{SDS}(\mathrm{M} \pm 1 \mathrm{SDS})$. Retardation in physical development was diagnosed if the gap ranged from minus 1 to minus $2 \mathrm{SD}$; subnanizm - from minus 2 to minus 3 SD; Nanism - from minus 3 SD and more. Atlas of W. W. Greulich, S. P. 
Pyle (1993) was used to determine bone age. To determine the degree of BAretardation from the passport age, $\mathrm{OC}$ was determined which is the ratio of the $\mathrm{X}$ ray age to the passport one. All children hadthyroid gland ultrasound and thyroid hormoneswere determined.

The level of the growth hormone (GH) in blood plasma was determined by the immune-chemiluminescence method on IMMULITE 2000XPi, Siemens Healthcare Diagnostics Inc, USA, using the standard set (basal level, somatotropic hormone release peak during a clonidine assay, and nocturnal release 2 hours after falling asleep). Levels $10 \mathrm{ng} / \mathrm{ml}$ and higherwere established as a norm of stimulated secretion of GH in standard samples. The release of GH after the test increased at least 5 timesin healthy childrenin comparison with the background value. The content of IGF-1 was determined once in the morning blood test by a solid-phase enzyme-linked immunosorbent sandwich method using a set of reagents "DRG" (Germany).

The content of zinc in blood plasma was determined using an X-ray fluorescence spectrometer «ElvaX-med» (Ukraine) based on the method of performing measurements of the content of chemical elements in blood plasma (MVB 081 / 12-0468-07). For zinc in the plasma, a venous blood sample was carried out in an amount not less than $1.0 \mathrm{ml}$. The sample was dried in a drying cabinet.

The results of the study are statistically processed using the packages of computer programs "Statistica" for Windows 8.0.0. (SPSS I.N.C.; 1989-1997), Statistics V.6.0 (Statsoft Inc., 1984-1996). The likelihood of the difference was taken into account by the magnitude of the probability $(\mathrm{p}<0,05)$.

The research is based on the main provisions of the ICH GCR and the Helsinki Declaration of the World Medical Association for Biomedical Research, where the person is their object (World Medical Association Declaration Helsinki 1964, 2000, 2008), the Council of Europe Convention on Human Rights and Biomedicine (2007).

\section{RESULTS}

The distribution of children who participated in the study is presented in Table 1 and Figure 1.

The body proportions, features of the face, the presence of stigmas diesembriogenesis, condition of hair, skin, voice of voice, body weight, state of genital organs, psychomotor development of a child were examined. The diffuse goiter was found in 10 children, autoimmune thyroiditis - in 2 children, primary hypothyroidism - in 1 child.
TABLE 1. Distribution of children who participated in the study

\begin{tabular}{|l|c|c|}
\hline Nosology & $\begin{array}{c}\text { Number } \\
\text { of patients } \\
\text { (boys/girls) }\end{array}$ & $\%$ \\
\hline CompleteSomatotropic insufficiency & $10(8 / 2)$ & 23.8 \\
\hline PartialSomatotropic insufficiency & $12(8 / 4)$ & 28.5 \\
\hline Inactive hormone growth syndrome & $4(3 / 1)$ & 9.5 \\
\hline Family-constitutional short stature & $14(8 / 6)$ & 33.3 \\
\hline Genetically determined short stature & $2(1 / 1)$ & 4.7 \\
\hline TOTAL & 42 & 100.0 \\
\hline
\end{tabular}

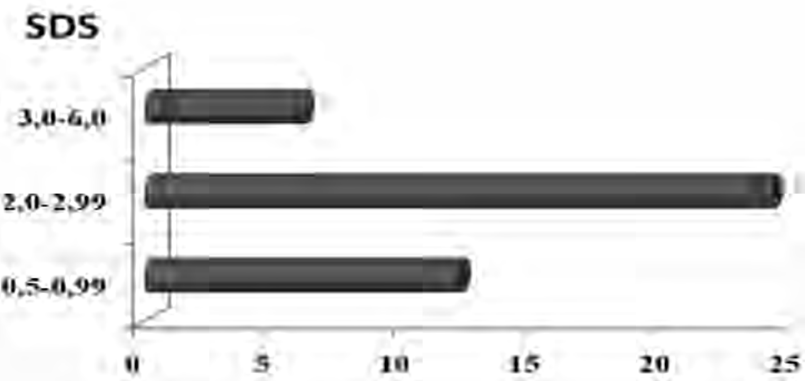

FIGURE 1. Distribution of the examined children by the standard deviation score (SDS)

The patients' main complaint was the inhibition of the growth rate to $1-3 \mathrm{~cm}$ per year over the past few years. In 5 children, the growth rate has been low since their birth. The maximum growth rate in children with short stature, depending on the cause of the retardation, was in cases of somatotropic insufficiency, the syndrome of a biologically inactive growth hormone - from $4.1 \mathrm{~cm} /$ year to $1.6 \mathrm{~cm} /$ year (on average $3.4 \pm 0.9 \mathrm{~cm} /$ year), with a family-constitutional short stature - from $5.7 \mathrm{~cm} /$ year to $3.3 \mathrm{~cm} /$ year (an average of $4.5 \pm 1.0 \mathrm{~cm} /$ year). According to the results of the clinical examination, in patients with growth retardation, a different degree from physical development delay (minus 1.05 SDS) to nasal fixation (minus 3-6.0 SDS) was recorded against the background of proportional body structure and lack of dysembriogenic stigma. The observed body mass deficiency was proportional to growth retardation. BMI in most children was within the mean values and amounted to $11.5-24.9 \mathrm{~kg} / \mathrm{m} 2$, only 4 children exceeded $25 \mathrm{~kg} / \mathrm{m} 2$. In the study of bone age, the lagging of the skeletal maturation for $5.5 \pm 0.4$ years is established. In all children with short stature, a significant lag in growth in all age groups was found to be greater than minus 2.5 SDS and a probable decrease in mean growth rates in comparison to the control group $(\mathrm{p}<0.01$, Table 2$)$. A significantly lower BA in boys than girls $(p<0.05)$ have been detected in primary school children age. The average lag in the BAin children of this age group was probably more pronounced in boys than in girls $(\mathrm{p}<0.05)$. 
TABLE 2. Indices of height, body weight, BMI, bone marrow in patients with short stature,

$(M \pm m)$

\begin{tabular}{|l|c|c|c|}
\hline Index & $\begin{array}{c}\text { Children with somatotropic } \\
\text { insufficiency }\end{array}$ & $\begin{array}{c}\text { Children with a family- } \\
\text { constitutional short stature }\end{array}$ & $\begin{array}{c}\text { Children of the } \\
\text { control group }\end{array}$ \\
\hline Growth, $\mathrm{cm}$ & $111.89 \pm 1.15$ & $123.98 \pm 1.09$ & $134.3 \pm 1.71^{*}$ \\
\hline $\mathrm{BMI}, \mathrm{kg} / \mathrm{m}^{2}$ & $17.03 \pm 0.21$ & $19.91 \pm 0.28$ & $22.18 \pm 0.57^{*}$ \\
\hline $\mathrm{BA}$, years & $6.23 \pm 0.21$ & $8.19 \pm 0.32$ & $9.8 \pm 0.3^{*}$ \\
\hline BA retardation, years & $2.39 \pm 0.06$ & $1.74 \pm 0.15$ & - \\
\hline GR, cm & $3.12 \pm 0.04$ & $4.59 \pm 0.19$ & \\
\hline SDS & $-2.91 \pm 0.08$ & $-2.13 \pm 0.07$ & - \\
\hline
\end{tabular}

Note. ${ }^{*}-p<0.05$, the probability of changes in the indicators relative to the comparison group

TABLE 3. Indicators of GH and IGF-1 in children with short stature rates

\begin{tabular}{|c|c|c|c|c|c|c|c|c|c|c|c|c|}
\hline \multirow{3}{*}{ Index } & \multicolumn{12}{|c|}{ Age (years) } \\
\hline & \multicolumn{3}{|c|}{$3-6$} & \multicolumn{3}{|c|}{$7-12$} & \multicolumn{3}{|c|}{$13-15$} & \multirow{2}{*}{\multicolumn{3}{|c|}{ Control Group }} \\
\hline & 1 & 2 & 3 & 1 & 2 & 3 & 1 & 2 & 3 & & & \\
\hline $\mathrm{GH}$, & $2.1 \pm$ & $11.9 \pm$ & $18.1 \pm$ & $2.0 \pm$ & $12.5 \pm$ & $16.6 \pm$ & $2.1 \pm$ & $13.1 \pm$ & $18.4 \pm$ & $2.4 \pm$ & $14.9 \pm$ & $21.2 \pm$ \\
\hline $\mathrm{ng} / \mathrm{ml}$ & 0.1 & 0.4 & 1.3 & 0.1 & 1.4 & 1.1 & 0,1 & 0.1 & 0.5 & $0.1^{*}$ & $1.2^{*}$ & $1.0^{*}$ \\
\hline IGF-1, ng / ml & \multicolumn{3}{|c|}{$70.4 \pm 8.1^{*}$} & \multicolumn{3}{|c|}{$139.7 \pm 15.1 *$} & \multicolumn{3}{|c|}{$198.2 \pm 18.7^{*}$} & \multicolumn{3}{|c|}{$231.4 \pm 11.5$} \\
\hline
\end{tabular}

Note. 1-background; 2 - night spontaneous peak; 3 - Clonidine test. ${ }^{*}-p<0.05$, the probability of changes in the indicescompared to the control group.

Indicators of GH and IGF-1 in children with short stature rates and control groups are presented in Table 3 .

According to the results of the study, it was detected that the level of zinc in the blood plasma is reducedin $90.4 \%$ of children with short stature. On average, the zinc level in the blood plasma of children

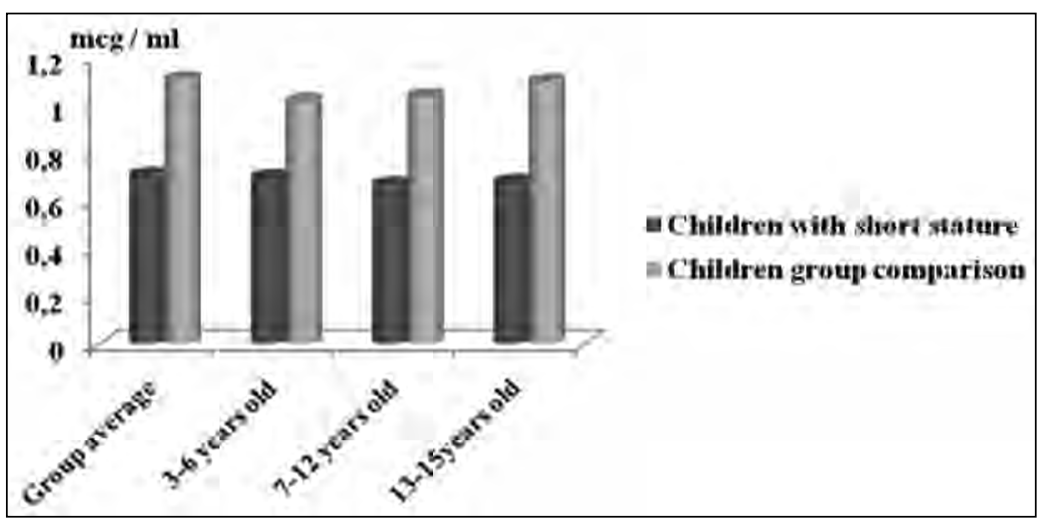

FIGURE 2. Zinc levels in the blood plasma of examined children $(p<0.001)$

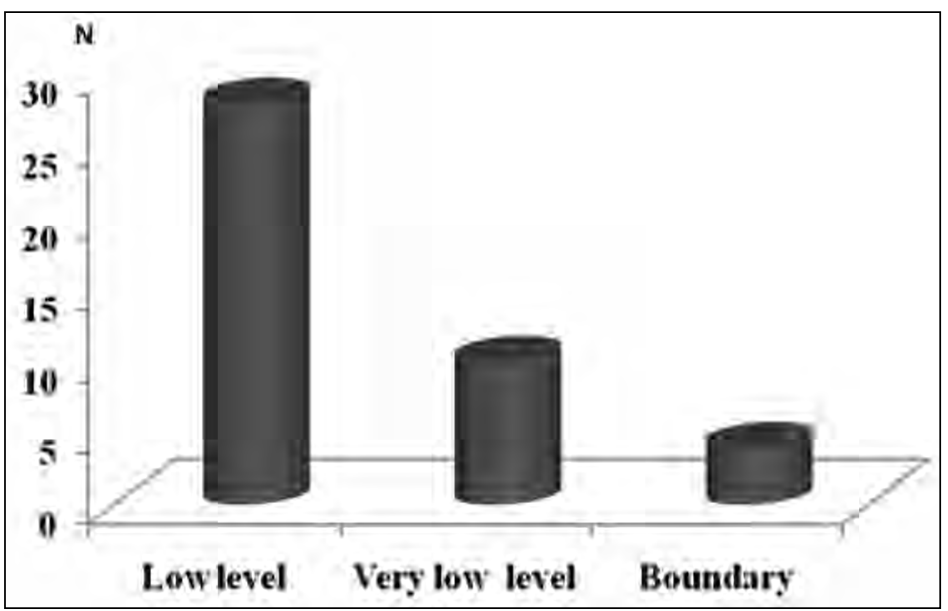

with short stature was $0.71 \pm 0.03 \mu \mathrm{g} / \mathrm{ml}$, which is significantly lower $(p<0.001)$ for the mean zinc level in the children of the control group - $1.11 \pm 0.02 \mu \mathrm{g} /$ $\mathrm{ml}$ (Fig. 2). In all age groups, a significant decrease in zinc values in plasma compared to those in the corresponding age group of the control group was detected. 
In 28 children the level of zinc was significantly lower, in 10 cases it was very low and in the rest of the cases it had lower bound values (Fig. 3). At the same time, in children of the control group, the reduction in zinc level occurred only in 2 children, very low rates were not recorded. Indices of zinc in blood plasma in children with somatotropic insufficiency were the lowest and averaged $0.66 \pm 0.03 \mu \mathrm{g} / 1, \mathrm{p}<0.05$.

The probable difference in the zinc level in blood plasma of children with short stature, depending on the gender, was not found in neither group of children with growth retardation nor in the control group.

We have analyzed the zinc level in blood plasma of children depending on SDS (Table 4).

TABLE 4. The level of zinc in blood plasma in children with short stature depends from the degree of growth retardation

\begin{tabular}{|l|c|}
\hline SDS & $\begin{array}{c}\text { Zinc level in blood plasma } \\
(\mathbf{M} \pm \mathbf{m}, \boldsymbol{\mu g} / \mathbf{m l})\end{array}$ \\
\hline$-0.5-1.99, \mathrm{n}=12$ & $0.70 \pm 0.03^{*}$ \\
\hline$-2.0-2.99, \mathrm{n}=24$ & $0.72 \pm 0.04^{*}$ \\
\hline$-3.0-6.0, \mathrm{n}=6$ & $0.65 \pm 0.03^{*}$ \\
\hline Control Group, $\mathrm{n}=44$ & $1.03 \pm 0.03$ \\
\hline
\end{tabular}

Note. ${ }^{*}-p<0.05$, the probability of changes in the indices compared to the control group

The lowest levels of zinc were observed in the group of children with the maximum growth retardation, but no significant differences in zinc level in blood plasma between these subgroups were observed.

\section{DISCUSSION}

$\mathrm{Zn}$ is important for the metabolic activity of more than two hundred enzymes. It is essential for cell replication, and deoxyribonucleic acid (DNA) and protein synthesis. $\mathrm{Zn}$ deficiency in humans is widespread throughout the world. This could be explained by the fact that intakes of animal products and animal protein are very low due to low socio-economic status of the population. Zn deficiency is reported to be associated with impairment of growth, testicular functions, appetite, and sense of taste, delay in wound healing, immune resistance and memory. Zn deficiency interferes with the metabolism of thyroid hormones, androgens and growth hormone [31]. It is not known what mechanism is responsible for growth retardation in $\mathrm{Zn}$ deficiency and how $\mathrm{Zn}$ therapy stimulates growth in children. The principal regulator of growth in the body is the GH-IGF system [32].

The relationship between $\mathrm{Zn}$ and GH-IGF system and how $\mathrm{Zn}$ therapy stimulates growth in children has not been clearly defined in humans. Controversy ex- ists about the effect of zinc on growth and the GHIGF system. Zinc supplementation has been shown to stimulate linear growth in zinc-deficient children. However the mechanism of this effect has not been well characterized. It appears that $\mathrm{Zn}$ supplementation has positive effects on growth and IGF-1 levels in various groups of $\mathrm{Zn}$-deficient children. However, the exact mechanism of Zn deficiency and the mechanism by which $\mathrm{Zn}$ supplementation affects $\mathrm{GH}$ secretion and IGF-1 levels is not well delineated. Furthermore, the effect of $\mathrm{Zn}$ supplementation on the GH-IGF axis in non $\mathrm{Zn}$-deficient short children is not known. Some studies have reported positive effects of $\mathrm{Zn}$ supplementation on growth in various groups of $\mathrm{Zn}$-deficient children [33-34]. However, in some studies, this effect was not observed [35-36]. We aimed to assess GH-IGF-Zn axis in short children. We found a low zinc level to be common in children with idiopathic short stature, whereas actual zinc deficiency was rare. However, other as yet unknown mechanisms not associated with the growth hormone (GH)-IGF-1 axis could be involved in growth retardation in idiopathic short stature.

According to the results of the study [37]. Zn supplementation increased basal IGF-I, IGFBP-3, alkaline phosphatase and osteocalcin without changing $\mathrm{GH}$ response to clonidine. Zinc supplementation did not affect sensitivity to exogenous $\mathrm{GH}$ as tested by IGF-I and IGFBP-3 generation test. These results suggest a direct stimulatory effect of zinc on serum IGFIGFBP-3, alkaline phosphatase and osteocalcin. Cesur et al, 2009 [38] found that serum IGF-1 and IGFBP-3 were below normal reference ranges in $96.6 \%$ and $100 \%$ of their short children with $\mathrm{Zn}$ deficiency which is close to our findings $(90,4 \%$ and $100 \%$ respectively).

On the other hand, an experimental study in rats [39] showed that restoration of normal circulating levels of IGF-1 and IGFBP-3 by recombinant IGF-1 infusion failed to reverse the growth retardation induced by $\mathrm{Zn}$ deficiency. They suggested that growth retardation related to $\mathrm{Zn}$ deficiency is caused not only by low serum IGF-1 concentrations, but also by inhibition of the anabolic actions of IGF-1. Moreover, it has been shown that $\mathrm{Zn}$ deficiency also leads to alterations in the distribution of serum IGFBPs, in addition to lower circulating IGF-1 concentrations [40]. This theory was further supported by the strong positive correlations between serum $\mathrm{Zn}$ and each of IGF1, IGF-1 SDS and IGFBP-3 levels reported in our study. In addition, other studies [41] suggested a state of GH resistance rather than GHD in case of $\mathrm{Zn}$ deficiency. 
Need to planned a prospective study is to assess the effect of zinc supplementation on growth parameters in children.

\section{CONCLUSIONS}

Zinc deficiency in the blood plasma was observed in most children with short stature $(90.4 \%)$, and 10 cases of them have a very low zinc level. Age and

\section{REFERENCES}

1. Chasapis CT, Loutsidou AC, Spiliopoulou CA, Stefanidou ME. Zinc and human health: An update. Arch Toxicol. 2012; 86(4):521-34.

2. Tudor R, Zalewski PD, Ratnaike RN. Zinc in health and chronic disease. J Nutr Health Aging. 2005; 9(1):45-51.

3. Chao HC, Chang YJ, Huang WL. Cut-off serum zinc concentration affecting the appetite, growth, and nutrition status of undernourished children supplemented with zinc. Nutr Clin Pract. 2018;33:701-710.

4. Petry N, Olofin I, Boy E et al.The effect of low dose iron and zinc intake on child. micronutrient status and development during the first 1000 days of life: A systematic review and meta-analysis. Nutrients. 2016; 8:773.

5. Lima AS, Cardoso BR, Cozzolino SF. Nutritional status of zinc in children with Down syndrome. Biol Trace Elem Res. 2010 Jan; 133(1):20-8.

6. Perrone L, Salerno M, Gialanella $G$ et al. Long-term zinc and iron supplementation in children of short stature: Effect of growth and on trace element content in tissues. J Trace Elem Med Biol. 1999 Jul; 13(1-2):51-6.

7. Abdelhamid N, Wahby A. Kandil ME. Zinc status in infants and children with cholestatic liver diseases and its effect on growth. Bulletin of the National Research Centre. 2019, 43:121.

8. Alves CX, Vale SH, Dantas MM et al. Positive effects of zinc supplementation on growth, GH, IGF1, and IGFBP3 in eutrophic children. J Pediatr Endocrinol Metab. 2012; 25(9-10):881-7.

9. Lingamaneni Prashanth, Kiran Kumar Kattapagari, Ravi Teja Chitturi et al. A review on role of essential trace elements in health and disease. J. of Dr. NTR University of Health Sciences. 2015; Vol. 4 (2): 75-85.

10. Moran VH, Stammers AL, Warthon M et al. Medina The Relationship between Zinc Intake and Serum/Plasma Zinc Concentration in Children: A Systematic Review and Dose-Response Meta-Analysis. Nutrients 2012; 4:841-858.

11. Cetin I, Koletzko B, Moreno LA, Matthys C. Relevance of European alignment for micronutrients' recommendation regarding pregnant and lactating women, infants, children and adolescents: An insight into preliminary steps of EURRECA. Matern. Child Nutr. 2010; 6:3-4.

12. 12. SchimmelM, Nur $E$, Mairuhu $W$ et al. Urinary zinc loss in sickle cell disease primarily due to increased bone degradation. Am J Hematol. 2016;91:E311-2.

13. Aaron GJ, Kariger P, Aliyu R, Flach M, Iya D, Obadiah M et al. A multi-micronutrient beverage enhances the vitamin $A$ and zinc status of Nigerian primary school children. Journal of Nutrition. 2011; 141:1565-72

14. Kapil U, Jain K. Magnitude of zinc deficiency amongst under five children in India. Indian Journal of Pediatrics. 2011;78:1069-72.

15. Park KH, Park B, Yoon DS et al. Zinc inhibits osteoclast differentiation by suppression of $\mathrm{Ca} 2+-$ Calcineurin-NFATc1 signaling pathway. Cell Commun. Signal. 2013; 11:P. 74-76.

16. Yamaguchi M. Role of nutritional zinc in the prevention of osteoporosis. Mol. Cell Biochem. 2010; 338, (1-2): 241-254.

17. Olivares M, Pizarro F, Romana DL. Effect of zinc sulphate fortificant on iron absorption from low extraction wheat flour co-fortified with gender dependency in blood zinc contents were not detected. The lowest level of zinc in the blood plasma was observed in the group of children with the greatest growth retardation. The results of the study indicate the urgent need for zinc deficiency correction in patients with short statureby diet expansion incorporating food enriched with the microelement or the designation of appropriate zinc preparations. Diet expansionmay be the subject of further research.

\section{Conflict of interest: none declared Financial support: none declared}

ferrous sulphate. Biological Trace Element Research. 2013; 151:471-5.

18. Das JK, Kumar R, Salam RA, Bhutta ZA. Systematic review of zinc fortification trials. Annals of Nutrition and Metabolism 2013; 62(Suppl 1):44-56.

19. Hamza RT, Hamed Al, Sallam MT. Efect of zinc supplementation on growth hormone-insulin growth factor axis in short Egyptian children with zinc deficiency Italian J. Pediatr. 2012;38: 21-25.

20. Imdad A, Bhutta ZA. Effect of preventive zinc supplementation on linear growth in children under 5 years of age in developing countries: A meta-analysis of studies for input to the lives saved tool. BMC Public Health. 2011; 11 (3):22.

21. Bol'shova OV, Pakhomova VH, Sprynchuk NA. Zinc status in children and adolescents with growth hormone deficiency. Lik Sprava. 2013;(5):70-5. Ukrainian.

22. Mayo-Wilson E, Junior JA, Imdad A et al. Zinc supplementation for preventing mortality, morbidity, and growth failure in children aged 6 months to 12 years of age [Electronic resource]. Cochrane Database Syst. Rev. 2014; 15(5):CD009384.

23. Quitmann J, Rohenkohl A, Bullinger M et al. Parental perception of health-related quality of life in children and adolescents with short stature: literature review and introduction of the parent-reported QoLISSY instrument. Pediatr. Endocrinol. Rev. 2013; 11(2): 147-160.

24. Klatka A, Błażewicz M, Partyka M et al. Concentration of selected metals in whole blood, plasma, and urine in short stature and healthy children. Biol. Trace Elem. Res. 2015;166(2):142-148.

25. Himoto T, Masaki T Associations between zinc deficiency and metabolic abnormalities in patients with chronic liver disease. Nutrients. 2018; 10:88.

26. Perondi C, Sandri G, Machado C, Tonel D, Weber J et al. Blood Zinc Levels and Oxidative Stress Parameters in Children and Adolescents with Down Syndrome. J Syndromes. 2018;4(1):6.

27. Angeles-Agdeppa I, Magsadia CR, Capanzana MV. Fortified juice drink improved iron and zinc status of school children. Asia Pacific Journal of Clinical Nutrition. 2011;20:535-43.

28. Bardosono S, Dewi LE, Sukmaniah S, Permadhi I, Eka AD. Lestarina L. Effect of a six-month iron-zinc fortified milk supplementation on nutritional status, physical capacity and speed learning process in Indonesian underweight schoolchildren: Randomized, placebocontrolled. Medical Journal of Indonesia. 2009;18:193-202.

29. Shah D. Magnitude of zinc deficiency and efficacy of zinc. Indian Journal of Pediatrics. 2011;78:1140-1.

30. Ebrahimi S, Pormahmodi A, Kamkar A. Study of zinc supplementation on growth of schoolchildren in Ysuj, Southwest of Iran. Pakistan Journal of Nutrition. 2006;5:341-2.

31. Bagherani N, Smoller BR. An overview of zinc and its importance in dermatology- Part I: Importance and function of zinc in human beings. Glob Dermatol. 2016; 3(5): 330-336.

32. Nakamura T, Nishijama S, Futagoishi Y, Matsuda I, Higashi A: Mild to moderate zinc deficiency in short children: Effect of zinc supplementation on linear growth velocity. J Pediatr. 1993; 123: 65-69. 
33. Nishi Y, Hatano S, Aihara K, Fujie A, Kihara M. Transient partial GH deficiency due to zinc deficiency. Am Coll Nutr. 1989, 8: 93-97.

34. Yoshida K, Urakami T, Kuwabara R, Morioka I. Zinc deficiency in Japanese children with idiopathic short stature. J Pediatr Endocrinol Metab. 2019;32(10):1083-1087.

35. Hershkowitz E, Printzman L, Segev Y, Levy J, Philip M. Zinc supplementation increases the level of serum IGF-I but does not promote growth in infants with nonorganic failure to thrive. Horm Res. 1999; 52: 200-204.

36. Yazbeck N, Hanna-Wakim R, Rafei R et al. Dietary Zinc Intake and Plasma Zinc Concentrations in Children with Short Stature and Failure to Thrive. Ann Nutr Metab. 2016;69(1):9-14.

37. Imamoğlu S, Bereket A, Turan S, Taga Y, Haklar G. Effect of zinc supplementation on growth hormone secretion, IGF-I, IGFBP-3, somatomedin generation, alkaline phosphatase, osteocalcin and growth in prepubertal children with idiopathic short stature. J Pediatr Endocrinol Metab. 2005;18(1):69-74.

38. Cesur Y, Yordam N, Dogan M: Serum Insulin-like Growth Factor-I and Insulin-like Growth Factor Binding Protein-3 Levels in Children with Zinc Deficiency and the Effect of Zinc Supplementation on these Parameters. J Pediatr Endocrinol Metab. 2009; 22: 1137-1143.

39. Ninh NX, Mailer D, Verniers J, Lause P, Ketelslegers JM, Thissen JP. Failure of exogenous IGF-I to restore normal growth in rats submitted to dietary zinc deprivation. J Endocrinol. 1998;159: 211-217.

40. Clegg MS, Keen CL, Donovan SM. Zinc deficiency induced anorexia influences the distribution of serum insulin-like growth factor-binding proteins in the rat. Metabolism. 1995; 44: 1495-1501.

41. Cunnane SC. Zinc Clinical and Biochemical Significance. CRC Press Book. 1st Edition. 2017:221p. 